\title{
The origin of the asymmetry in the Iceland hotspot along the Mid-Atlantic Ridge from continental breakup to present-day
}

\author{
Samuel M. Howell ${ }^{\mathrm{a}, *}$, Garrett Ito ${ }^{\mathrm{a}}$, Asbjørn J. Breivik ${ }^{\mathrm{b}}$, Abhishek Rai ${ }^{\mathrm{b}}$, Rolf Mjelde ${ }^{\mathrm{c}}$, \\ Barry Hanan $^{\mathrm{d}}$, Kaan Sayit ${ }^{\mathrm{d}}$, Peter Vogt ${ }^{\mathrm{e}}$
}

a Dept. of Geology and Geophysics, SOEST, University of Hawaiti at Mānoa, 1680 East-West Rd., Honolulu, HI 96822, USA

b Department of Geosciences, University of Oslo, P.O. Box 1047, Blindern, 0316 Oslo, Norway

c Department of Earth Sciences, University of Bergen, Allegt. 41, NO-5007 Bergen, Norway

d Department of Geological Sciences, San Diego State University, San Diego, CA 92182-1020, USA

e Marine Science Institute, University of Santa Barbara, Santa Barbara, CA 93106-6150, USA

\section{A R T I C L E I N F O}

\section{Article history:}

Received 14 June 2013

Received in revised form 20 December 2013

Accepted 6 February 2014

Available online $\mathrm{xxxx}$

Editor: Y. Ricard

\section{Keywords:}

North Atlantic

mantle plumes

mid-ocean ridges

continental rifting

hotspots

dehydration

\begin{abstract}
A B S T R A C T
The Iceland hotspot has profoundly influenced the creation of oceanic crust throughout the North Atlantic basin. Enigmatically, the geographic extent of the hotspot influence along the Mid-Atlantic Ridge has been asymmetric for most of the spreading history. This asymmetry is evident in crustal thickness along the present-day ridge system and anomalously shallow seafloor of ages $\sim 49-25$ Ma created at the Reykjanes Ridge (RR), SSW of the hotspot center, compared to deeper seafloor created by the nowextinct Aegir Ridge (AR) the same distance NE of the hotspot center. The cause of this asymmetry is explored with 3-D numerical models that simulate a mantle plume interacting with the ridge system using realistic ridge geometries and spreading rates that evolve from continental breakup to present-day. The models predict plume-influence to be symmetric at continental breakup, then to rapidly contract along the ridges, resulting in widely influenced margins next to uninfluenced oceanic crust. After this initial stage, varying degrees of asymmetry along the mature ridge segments are predicted. Models in which the lithosphere is created by the stiffening of the mantle due to the extraction of water near the base of the melting zone predict a moderate amount of asymmetry; the plume expands NE along the AR $\sim 70-80 \%$ as far as it expands SSW along the RR. Without dehydration stiffening, the lithosphere corresponds to the near-surface, cool, thermal boundary layer; in these cases, the plume is predicted to be even more asymmetric, expanding only $40-50 \%$ as far along the AR as it does along the RR. Estimates of asymmetry and seismically measured crustal thicknesses are best explained by model predictions of an Iceland plume volume flux of $\sim 100-200 \mathrm{~m}^{3} / \mathrm{s}$, and a lithosphere controlled by a rheology in which dehydration stiffens the mantle, but to a lesser degree than simulated here. The asymmetry of influence along the present-day ridge system is predicted to be a transient configuration in which plume influence along the Reykjanes Ridge is steady, but is still widening along the Kolbeinsey Ridge, as it has been since this ridge formed at $\sim 25 \mathrm{Ma}$.
\end{abstract}

(C) 2014 Elsevier B.V. All rights reserved.

\section{Introduction}

The North Atlantic region has been influenced by anomalously profuse magmatism associated with the Iceland hotspot to varying degrees from before the time of continental breakup until present-

\footnotetext{
* Corresponding author. Tel.: +1 5762470.

E-mail addresses: howellsm@hawaii.edu (S.M. Howell), gito@hawaii.edu (G. Ito), a.j.breivik@geo.uio.no (A.J. Breivik), a.k.rai@geo.uio.no (A. Rai), Rolf.Mjelde@geo.uib.no (R. Mjelde), barry.hanan@sdsu.edu (B. Hanan), kaansayit@hotmail.com (K. Sayit), ptr_vogt@yahoo.com (P. Vogt).
}

day. For example, residual basement depth (bathymetry corrected for sediment loading and subsidence with crustal age), which commonly correlates with crustal thickness, is anomalously shallow for $>2000 \mathrm{~km}$ along the margins of Greenland and Norway, as well as most of the basin surrounding Iceland (Fig. 1, Ito and van Keken, 2007). This shallow seafloor comprises most of the North Atlantic Igneous Province (e.g. Coffin and Eldholm, 1994; Holbrook et al., 2001; White, 1997). Northeast of Iceland, shallow topography surrounds the basin created by the now-extinct Aegir Ridge (AR). Conspicuously however, most of the AR basin (Norway Basin) itself is relatively deep (e.g. Vogt et al., 1981, 1982). Apparently, the 


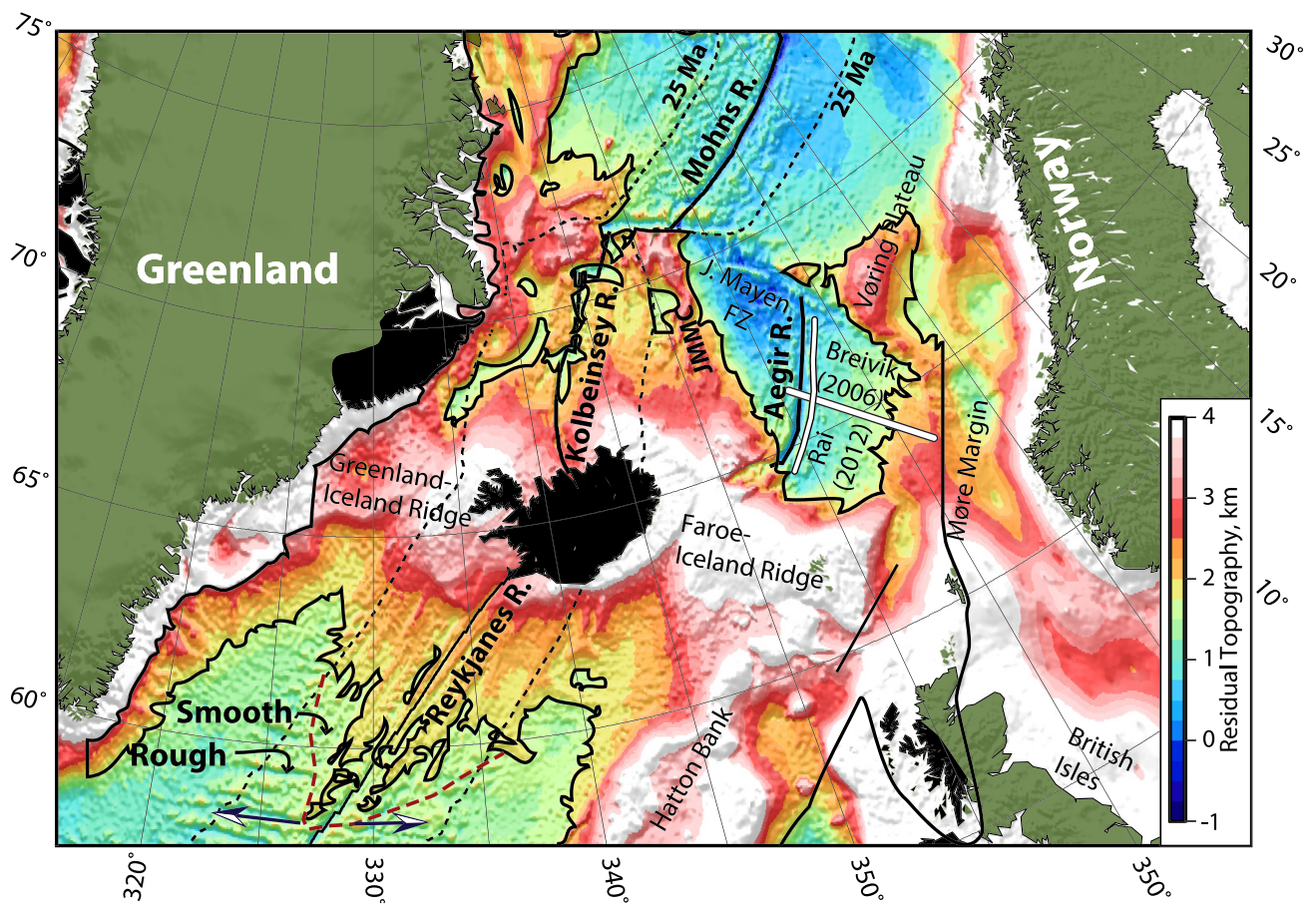

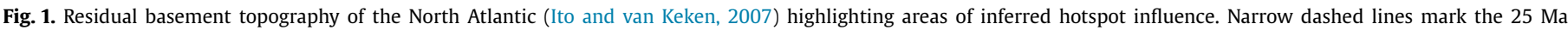

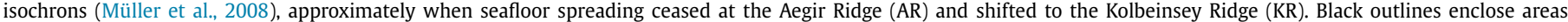

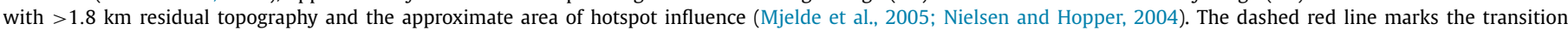

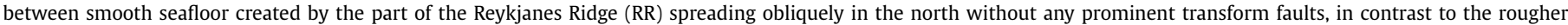

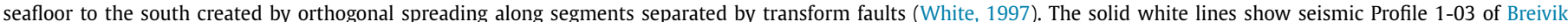

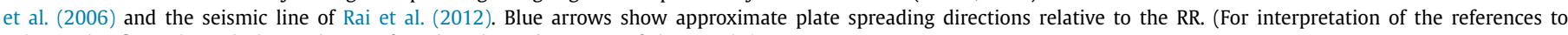
color in this figure legend, the reader is referred to the web version of this article.)

hotspot heavily influenced the areas west, east, and south of the basin, but had much less influence on the AR basin itself. Also peculiarly, the Iceland hotspot influence appears to extend less far north along the Kolbeinsey Ridge (KR) than south along the Reykjanes Ridge (RR) relative to Vatnajökull (e.g. Hooft et al., 2006; Schilling, 1999; Schilling et al., 1983), which marks the center of the Iceland hotspot, as confirmed by upper mantle tomography (Allen et al., 2002; Wolfe et al., 1997). (Shorttle et al., 2010 argue for a symmetric variation in bathymetry, but place their hotspot center south of the tomographic center of the hotspot.) Thus, the influence of the Iceland hotspot along the Mid-Atlantic Ridge appears to have been asymmetric throughout much of the history of seafloor spreading in the North Atlantic.

Constraints on the tectonic evolution provide more evidence for this asymmetry and clues to the possible causes. The breakup of Greenland and Norway began $\sim 55-54$ Ma (e.g. Torsvik et al., 2001) and was accompanied by extensive flood basalt volcanism and igneous intrusions along the continental margins to form a major magmatic phase of the North Atlantic Igneous Province (e.g. White and McKenzie, 1989). Seismic studies document igneous crustal thicknesses of up to $\sim 35 \mathrm{~km}$ along both continental margins near the center of the Iceland hotspot track, and thicknesses $\geqslant 15 \mathrm{~km}$ extending $\geqslant 1000 \mathrm{~km}$ along the margins to the north and south (Breivik et al., 2006; Holbrook et al., 2001; Mjelde et al., 2008; Voss et al., 2009). Shortly after breakup ( 54-52 Ma), oceanic crust began forming along three main spreading centers, the RR, AR, and Mohns Ridge (MR) (Fig. 2). Average half-spreading rates (29-33 km/Myr) and crustal thicknesses at this time were at their highest observed values (Fig. 3, Breivik et al., 2006, 2009; Smallwood and White, 2002; Voss et al., 2009). For example, oceanic crustal thickness was $\sim 8 \mathrm{~km}$ along the early AR (Breivik et al., 2006), as thick or thicker along much of the RR, and significantly thicker $(>30 \mathrm{~km}$ ) along the Iceland-Greenland and IcelandFaeroe volcanic ridges (e.g. Holbrook et al., 2001; Smallwood et al.,
1999). Shortly after continental breakup, the relative location of the hotspot center was likely near the margin of east Greenland (Fig. 2), although the lack of a documented age progression along the presumed hotspot track leads to large uncertainties in the relative location of the hotspot through time (e.g. Lawver and Müller, 1994; Mihalffy et al., 2008; Steinberger, 2000). In pre- and earlybreakup history, hotspot influence was widespread, with no clear asymmetry.

During $\sim 52-43 \mathrm{Ma}$, the average seafloor half-spreading rate along the $\mathrm{RR}, \mathrm{KR}$, and $\mathrm{AR}$ slowed to $\sim 12 \mathrm{~km} / \mathrm{Myr}$, and the influence of the hotspot on the AR, evident in crustal thickness, decreased significantly (Fig. 3). During 43-28 Ma, seafloor spreading at the AR was probably slower than at the RR and MR by as much as 30\% (Breivik et al., 2006; Mosar et al., 2002; Smallwood and White, 2002; Voss et al., 2009), likely related to lithospheric stretching or the very earliest stages of rifting at the KR. Crustal thickness generated from 43 to $28 \mathrm{Ma}$ along the middle and northern portions of the AR was only 3.5-5.5 km (Breivik et al., 2006), similar to that of normal (not hotspot influenced) oceanic crust at the same ultra-slow spreading rate of $\sim 7 \mathrm{~km} / \mathrm{Myr}$ (Dick et al., 2003; White et al., 2001). Along the 33 Ma isochron, crustal thickness is $\sim 4 \mathrm{~km}$ in the northern part of the AR and thickens to $\sim 7 \mathrm{~km}$ in the southernmost $\sim 250-300 \mathrm{~km}$ of the AR (Rai et al., 2012). Thicker crust with the slightly slower spreading to the south is opposite the correlation for normal ridges (Dick et al., 2003; White et al., 2001), and therefore suggests a modest degree of hotspot influence, restricted to the southern portion of AR.

By $\sim 30-28 \mathrm{Ma}$, seafloor spreading had begun migrating from south to north along the KR, separating the Jan Mayen microcontinent (JMMC) from Greenland (Fig. 2); by $\sim 25 \mathrm{Ma}$ the AR was extinct and spreading was completely transferred to the KR (Nunns, 1983; Vogt et al., 1980). Plume influence along the $\mathrm{RR}$ at this time is inferred from smooth basement topography created by the part of the RR spreading obliquely 

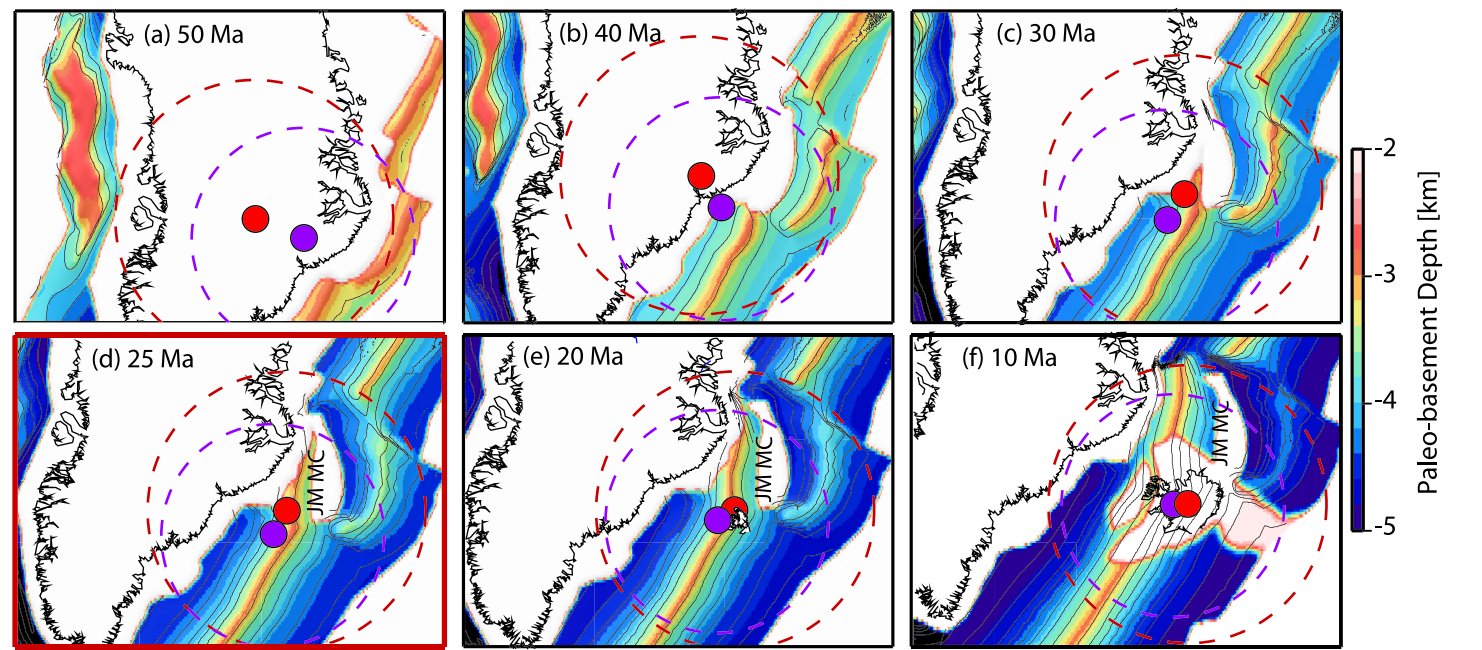

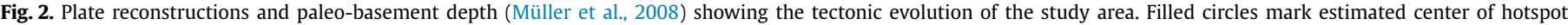

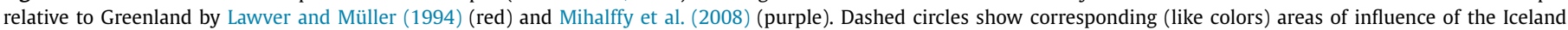

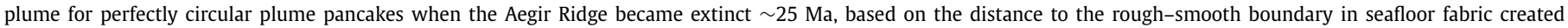
at the Reykjanes Ridge at $25 \mathrm{Ma}$. (For interpretation of the references to color in this figure legend, the reader is referred to the web version of this article.)

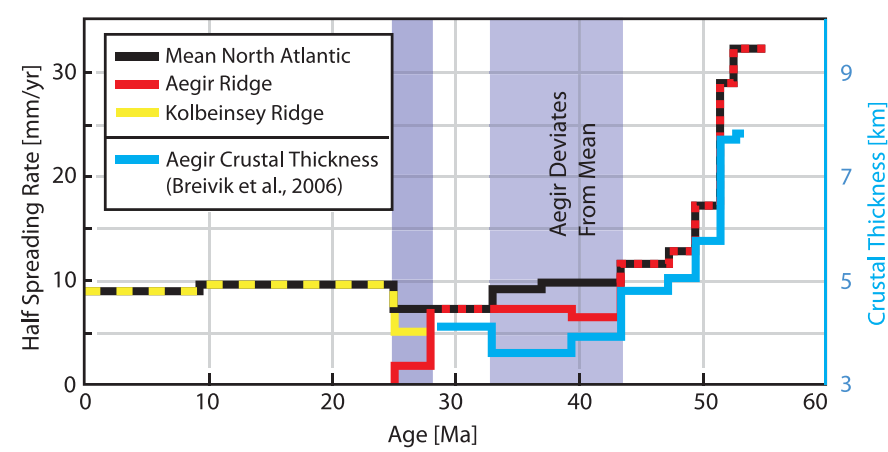

Fig. 3. Modeled spreading rate evolution for the North Atlantic. Geological estimates of the spreading rates at MR (Breivik et al., 2009; Voss et al., 2009), RR (Smallwood and White, 2002), AR (red, Breivik et al., 2006), and KR (yellow, Mosar et al., 2002) were averaged to create a mean North Atlantic spreading rate through time (black). Since $33 \mathrm{Ma}$, spreading rates by Mosar et al. (2002) for all four ridges are incorporated. The mean spreading rate (black) was used to model all of the active ridges at times when the geological estimates of their spreading rates were very similar (deviating by $<2 \mathrm{~mm} / \mathrm{yr}$ ). However, during times marked by shaded bands, the model Aegir and Kolbeinsey Ridges were assigned the low rates defined by the geological estimates, and the model Reykjanes and Mohns Ridges shared the same (faster) spreading rate, determined by the average (black) of their individual geological rates. The blue line shows the time evolution of seismically measured crustal thickness across the AR (Profile 1-03, Breivik et al., 2006). (For interpretation of the references to color in this figure legend, the reader is referred to the web version of this article.)

in the north without any prominent transform faults, in contrast to the rougher seafloor to the south, created by orthogonal spreading along segments separated by transform faults (Vogt and Avery, 1974; White, 1997). This "rough-smooth" boundary is interpreted to delineate the maximum extent of plume influence along the RR, and was 600-1200 km SSW of the Iceland hotspot. The same distance northeast from the projected hotspot center would encompass a large portion, if not all, of the AR (Fig. 2). The lack of thickened crust along most of the AR during all but the first 2-3 Myr of its spreading history indicates that the plume influence was asymmetric starting near $\sim 49-47 \mathrm{Ma}$, influencing the RR further SSW than the AR to the NE.

When considering the tectonic evolution, two hypotheses can be formulated as to the cause of the long-term asymmetry in the Iceland hotspot. (1) The asymmetric geometry of the ridges relative to each other and to the hotspot center leads to asymmetric hotspot influence. (2) Variations in lithospheric thickness, including the conduit-like, "inverted troughs" which form beneath the ridge axes, and thick lithosphere of the JMMC, promote plume expansion SW along the RR and impede plume expansion NE to the AR.

To test the above hypotheses about the comparatively restricted hotspot influence in the AR basin and to address the cause of asymmetric Iceland hotspot influence overall, we use 3-D numerical models that simulate a plume interacting with rifting continents and spreading ridges. The models simulate ridge geometries and spreading rates based on geological estimates from the time of continental breakup until present-day. Varied model parameters are plume volume flux, mantle viscosity, and rheology of the lithosphere, which controls the structure of the lithosphere. In one set of models, the lithosphere corresponds to the cool thermal boundary layer near the surface. In another set of models, the rheology is controlled by water content, and partial melting removes water from the solid leaving a stiff, dehydrated lithosphere, independent of the thermal boundary layer. We quantify the effects of the above variables on the asymmetry of a plume interacting with the ridge. Finally, we compare model predictions with observations to infer the volume flux of the Iceland plume and rheology of the lithosphere.

\section{Methods}

\subsection{Model setup}

We employ Citcom, a finite element code widely used to simulate mantle convection (e.g. Moresi and Gurnis, 1996; Zhong et al., 2000). Citcom solves the equations describing conservation of mass, conservation of momentum, and conservation of energy in a Cartesian coordinate system for a fluid with zero-Reynolds number and infinite Prandlt number (see supplementary material). The extended Boussinesq approximation is used to simulate the adiabatic temperature gradient and latent heat loss due to melting (Bianco et al., 2011). Model dimensions are $2400 \times 2800 \times 400 \mathrm{~km}$, with $289 \times 257 \times 65$ elements of size $8 \times 11 \times 6 \mathrm{~km}$ in the $x, y$, and $z$ directions, respectively (Fig. 4).

The structure of the stiff part of the plate, or lithosphere, is controlled by the rheology. One set of models simulates a "thermal lithosphere", which develops because viscosity varies as a standard Arrhenius function of temperature and pressure 


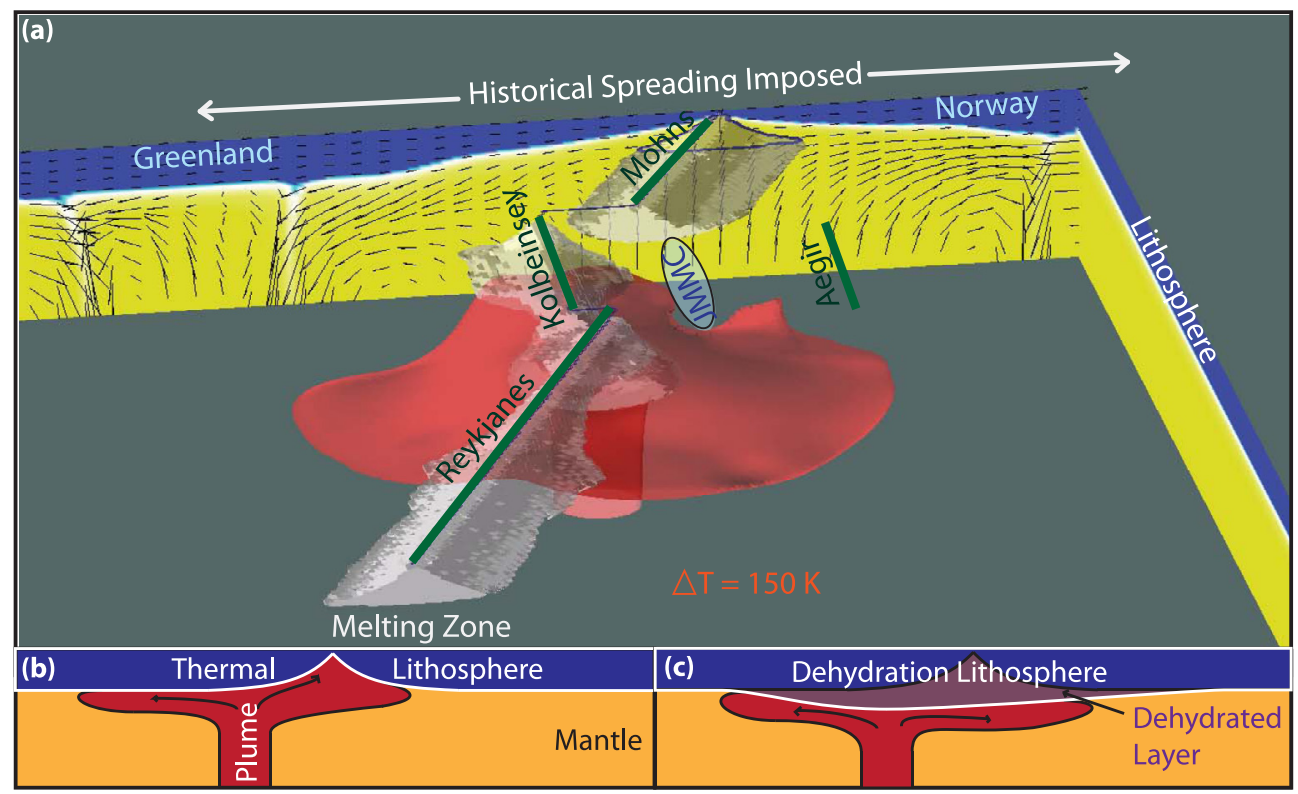

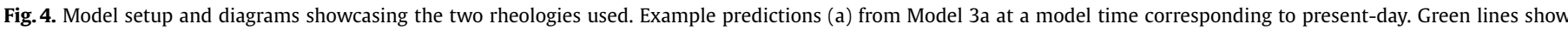

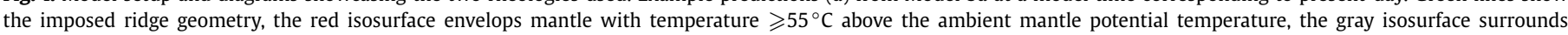

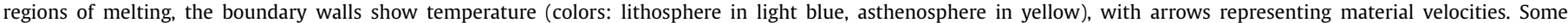

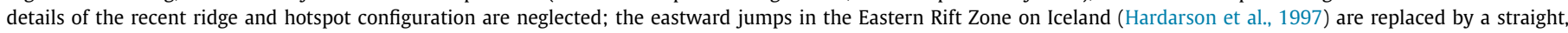

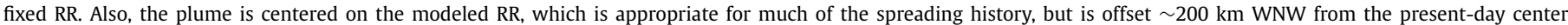

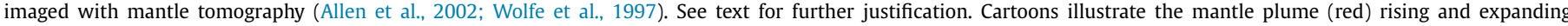

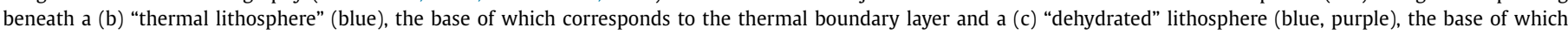
corresponds to the dry-solidus. (For interpretation of the references to color in this figure legend, the reader is referred to the web version of this article.)

(see supplementary material). The thermal lithosphere corresponds to the cool thermal boundary layer near the surface (Fig. 4(b)) and is therefore directly coupled to the geometry of the plates: it is thinnest beneath the ridges, thicker away from the ridge, and thickest beneath continents and the JMMC. In another set of models, viscosity also depends inversely on the fractional amount of water dissolved in the solid (Hirth and Kohlstaedt, 2003). The extraction of water at the base of the melting zone leads to a rapid increase in viscosity by two orders of magnitude, forming a thick "dehydrated" lithosphere (Hirth and Kohlstaedt, 2003). In this case, the dehydrated lithosphere is thickest near the plume center where the solidus is deepest and thins away from the plume center (Fig. 4(c), Ito et al., 1999), but the thickness variations are small compared to those of thermal lithosphere and do not relate directly to the shape of the plates.

The plume source is imposed as a hot circular patch on the bottom boundary of the model, with a peak excess temperature of $\Delta T=150 \mathrm{~K}$ at the plume center, decaying as a Gaussian function of radial distance, characterized by radius $r$, at which the temperature anomaly has decreased by a factor of $e$. The plume is centered on the Mid-Atlantic Ridge at all times. This simplification is consistent with the Greenland-Iceland and Faeroe-Iceland volcanic ridges, representing the hotspot tracks on both plates, with the hotspot being very near or at the ridge since continental breakup (Vink, 1984; White, 1988, 1997; Wilson, 1973).

Plate geometry is imposed with horizontal velocity boundary conditions on the top model surface, diverging at the ridge axes and constant in the plate interior (Fig. 4(a), plate motion is in the $x$ direction). The geometry is obtained from a polar projection of the North Atlantic rotated into the average spreading direction of the region. The plate separation rate is simulated as being spatially uniform, therefore the decrease in opening rate from north-tosouth along the AR is not simulated. The RR, AR, and MR are approximated with straight segments, with transforms parallel to the spreading direction. The straight segment that approximates the RR extends through Iceland, so the very recent ( $\sim 8 \mathrm{Ma}$, Garcia et al., 2008) eastward offset of the Northern Rift Zone is neglected for simplicity. The average North Atlantic spreading rate as it changes through time is used for all ridges, except at the AR when spreading rates significantly diverge from the average during $\sim 43-33 \mathrm{Ma}$, and at the KR, which spreads slower than average before the death of the AR (Fig. 3).

The initial conditions simulate the pre-rifted, continental lithosphere as a $\sim 100$-km-thick, cool thermal boundary layer (Breivik et al., 2009). The surface is held motionless to allow the plume to rise from the base to the top of the model, and for it to begin spreading like a "pancake" beneath the lithosphere. Once the pancake expands to a diameter of $\sim 2400 \mathrm{~km}$-the approximate extent of influence along the Greenland continental margin (Holbrook et al., 2001)-continental rifting and the seafloor spreading sequence initiates.

\subsection{Mantle melting and crustal accretion}

To investigate how the evolving mantle plume affects igneous crustal thickness, we solve for melt production and compute crustal thickness. Melting rate is calculated as the time rate of change of extent of melt depletion, $F$, using the parameterization of Katz et al. (2003) and by advecting $F$ with passive tracers (see Bianco et al., 2011 for details). The melt produced is assumed to instantaneously migrate directly opposite the spreading direction to the nearest ridge segment, where it is incorporated into the crustal accretion zone, which is $30 \mathrm{~km}$ wide across the ridge axis, for numerical stability. Crustal thickness, $T_{C}$, is computed at each point by solving the time-dependent advection equation in the Lagrangian reference of each spreading plates, using explicit forward differencing in time,

$$
\frac{D T_{c}}{D t}=q_{c}
$$


The left hand side is the material time derivative of $T_{c}$, and $q_{c}$ is the volume flux of melt delivered from the mantle per unit area within the crustal accretion zone.

\subsection{Tracking plume material}

For measurements of the lateral extent of plume influence, we use passive markers to track the advection of plume material. The markers were introduced at a depth of $200 \mathrm{~km}$ wherever excess mantle temperature is $>\Delta T / e$, then advected with the mantle flow. We use "width" to describe the extent of the plume pancake along the ridge axis (e.g., Ribe et al., 1995). This width is formally defined as the along-axis distance from the plume center to which the plume material contributes $>50 \%$ to the model crust. The widths along the Reykjanes and Aegir Ridges ( $W_{R R}$ and $W_{A R}$, respectively) are measured at $\sim 30 \mathrm{Ma}$, which is near the time the AR became extinct and close to the isochron along which the Rai et al. (2012) seismic refraction profile ran. In addition, the total radial distances of plume influence at $30 \mathrm{Ma}, R_{R R}$ and $R_{A R}$, are the distance from the plume center to the most distal extent of plume influence along the RR and AR, respectively. The ratios $W_{A R} / W_{R R}$ and $R_{A R} / R_{R R}$ measure the asymmetry of plume influence along the AR compared to the RR. Ratios of unity represent perfect symmetry; lower values represent greater asymmetry. The ratio of radial extents $R_{A R} / R_{R R}$ characterizes the asymmetry of the plume pancake, whereas $W_{A R} / W_{R R}$ addresses the apparent asymmetry in width along these ridges and does not include the offset between the plume center and the AR as part of the measurement.

\subsection{Model parameters}

Several properties are likely to influence along-axis widths. Plume volume flux $Q$ is known to be one primary control on the steady-state (symmetric) width $W$ to which a plume expands along a straight ridge, spreading at a rate of $U ; W \propto(Q / U)^{1 / 2}$ (Ribe et al., 1995). Plume volume flux $Q$ may also modulate the asymmetry of the plume pancake by influencing the strength of the part of mantle flow that is driven by plume buoyancy, which alone should be radially symmetric, relative to the part of the flow driven by the spreading plates, which, due to the asymmetric ridge geometry, should be asymmetric. Finally, variations in $Q$ as well as viscosity $\eta$ change the characteristic thickness of the hot plume pancake beneath the lithosphere $S$ (Ribe et al., 1995), where

$S=\left(\frac{48 \eta Q}{g \Delta \rho}\right)^{\frac{1}{4}}$,

in which $g$ is gravitational acceleration, and $\Delta \rho$ is the density contrast between the plume and the ambient mantle. When calculating $S$, we defined $\eta$ to be the lowest viscosity in the ponding plume pancake. The ratio of $S$ to the characteristic amount that the lithosphere thickens off-axis, $\Delta h$, is predicted to control the degree to which lithosphere structure influences the lateral expansion of the plume pancake (Ribe et al., 1995). If $S / \Delta h \gg 1$, then the pancake expands much like it would against a flat lithospheric base, whereas if $S / \Delta h \sim 1$, the expansion can be perturbed by a sloping base of the lithosphere (Ribe et al., 1995). In models in which the lithosphere is controlled by dehydration, the lithosphere does not thicken systematically away from the ridge axis, $S / \Delta h$ is always very large $(\gg 1)$, and therefore the asymmetric ridge geometry should have a smaller influence on making the plume asymmetric. If the lithosphere is thermally controlled, then $S / \Delta h$ is variable and can approach unity, in which case the asymmetric ridge geometry can have a larger influence on the shape of the plume pancake.
To modulate $Q, \eta$, and $S / \Delta h$, we vary three model input parameters: plume radius, $r$, Rayleigh number, $R a$ (higher $R a$ simulates lower plume viscosities), and water-independent versus water-dependent rheology (details given in Table 1 ). Ambient mantle potential temperature $\left(1325^{\circ} \mathrm{C}-1338^{\circ} \mathrm{C}\right)$ is varied with Rayleigh number to produce reasonable $(5.5-6.5 \mathrm{~km})$ crustal thicknesses for non-plume influenced, slow-spreading ridges (Dick et al., 2003; White et al., 2001). A range of plume volume fluxes are investigated $\left(95-446 \mathrm{~m}^{3} / \mathrm{s}\right)$ by varying plume radius $(65-180 \mathrm{~km})$ at four Rayleigh numbers $\left(5 \times 10^{5}-2 \times 10^{6}\right)$. About half of the calculations simulate a thermal lithosphere without the effects of dehydration stiffening, while the other half consider a dehydrated lithosphere that does include these effects. Model outputs are presented as maps of crustal thickness, volume fraction of plume-contributed crust and model seafloor ages, along with the widths $\left(W_{R R}\right.$ and $\left.W_{A R}\right)$ and radial distances $\left(R_{R R}\right.$ and $\left.R_{A R}\right)$ of plume influence along the Aegir and Reykjanes Ridges.

\section{Model results}

\subsection{General temporal behavior of the plume}

The evolution of the plume in an example model (Model 3a, Table 1) is shown in Fig. 5. Again, the plume is first allowed to expand beneath a stationary, thick continental plate; once it spans a diameter of $2400 \mathrm{~km}$, continental rifting begins. Right after continental breakup (54 Ma), the initially wide plume pancake quickly contracts as plume material fills the inverted trough (pseudo-triangular conduit) created in the rifted, thick continental lithosphere, and plate motion draws plume material away from the ridge axis. In the case shown, the pancake is nearly half its original radius at $\sim 47 \mathrm{Ma}$. The pancake is also already asymmetric: it extends further along the RR than along the AR, and has withdrawn completely from beneath the MR (Fig. 5).

From just after the model time of $\sim 47 \mathrm{Ma}$ until $\sim 30 \mathrm{Ma}$, the plume pancake widens slightly along the ridges (Fig. 5), largely due to a factor of $\sim 3$ reduction in spreading rate (Fig. 3). By $30 \mathrm{Ma}$, the pancake in this model is more than twice as wide along the RR as it is along the AR. The slow widening along the ridges continues in this model to $\sim 27 \mathrm{Ma}$ (not shown).

From 28-25 Ma, rifting at the KR begins in the south and propagates north at the expense of spreading at the AR. At $25 \mathrm{Ma}$ (not shown), the AR is fully extinct. The widening of the plume along the RR stagnates as plume material that would otherwise feed the RR now flows toward the KR (see $23 \mathrm{Ma}$, Fig. 5). From 25-15 Ma, the plume contracts along the KR in response to continental rifting, much like the initial plume contraction event at $54 \mathrm{Ma}$. Starting $\sim 10 \mathrm{Ma}$, the plume widens slightly along the KR. At the model time representing present-day, the plume pancake is still widening along the $\mathrm{KR}$, but has reached a minimum in width along the RR.

\subsection{Record of plume influence on the seafloor}

The predicted evolution is recorded in maps of crustal thickness and fractional contribution of the plume to the crust for models with two different plume fluxes, for both rheologies (Fig. 6). The model of high plume flux and thermal lithosphere is the same model presented in Fig. 5 (Model 3a, Fig. 6(a), (c)). The initial contraction of the pancake immediately following continental breakup results in long (tapered) bands of plume-influenced crust along the continental margins adjacent to uninfluenced crust (Fig. 6(a)). From the minimum plume width after the initial contraction, near seafloor age of $\sim 49 \mathrm{Ma}$, the extent of plume influence increases toward the $25 \mathrm{Ma}$ isochron along both ridges, although more extensively southward along the model RR than north along the AR. 
Table 1

Model parameters varied (all other parameters were kept constant).

\begin{tabular}{|c|c|c|c|c|c|}
\hline Parameter & $R a$ & $T_{p}$ & $r$ & $Q$ & \\
\hline Definition & Rayleigh number & Mantle potential temperature & Plume radius & Plume volume flux & Rheology \\
\hline Units & (Dimensionless) & $\left({ }^{\circ} \mathrm{C}\right)$ & $(\mathrm{km})$ & $\left(\mathrm{m}^{3} / \mathrm{s}\right)$ & \\
\hline Model 1a & $0.5 \times 10^{6}$ & 1338 & 0 & 0 & no dehydration \\
\hline Model 1b & $0.5 \times 10^{6}$ & 1338 & 0 & 0 & dehydration \\
\hline Model 2a & $0.5 \times 10^{6}$ & 1338 & 95 & 114 & no dehydration \\
\hline Model 2b & $0.5 \times 10^{6}$ & 1338 & 95 & 95 & dehydration \\
\hline Model 3a & $0.5 \times 10^{6}$ & 1338 & 130 & 232 & no dehydration \\
\hline Model 3b & $0.5 \times 10^{6}$ & 1338 & 130 & 178 & dehydration \\
\hline Model 4 & $0.5 \times 10^{6}$ & 1338 & 149 & 226 & dehydration \\
\hline Model 5a & $0.5 \times 10^{6}$ & 1338 & 180 & 446 & no dehydration \\
\hline Model 5b & $0.5 \times 10^{6}$ & 1338 & 180 & 303 & dehydration \\
\hline Model 6a & $1.0 \times 10^{6}$ & 1332 & 105 & 272 & no dehydration \\
\hline Model 6b & $1.0 \times 10^{6}$ & 1332 & 120 & 275 & dehydration \\
\hline Model 7a & $1.5 \times 10^{6}$ & 1328 & 89 & 263 & no dehydration \\
\hline Model 7b & $1.5 \times 10^{6}$ & 1328 & 102 & 289 & dehydration \\
\hline Model 8a & $2.0 \times 10^{6}$ & 1325 & 65 & 146 & no dehydration \\
\hline Model 8b & $2.0 \times 10^{6}$ & 1325 & 65 & 128 & dehydration \\
\hline Model 9a & $2.0 \times 10^{6}$ & 1325 & 82 & 276 & no dehydration \\
\hline Model 9b & $2.0 \times 10^{6}$ & 1325 & 88 & 268 & dehydration \\
\hline Model 10a & $2.0 \times 10^{6}$ & 1325 & 130 & 840 & no dehydration \\
\hline Model 10b & $2.0 \times 10^{6}$ & 1325 & 130 & 597 & dehydration \\
\hline
\end{tabular}

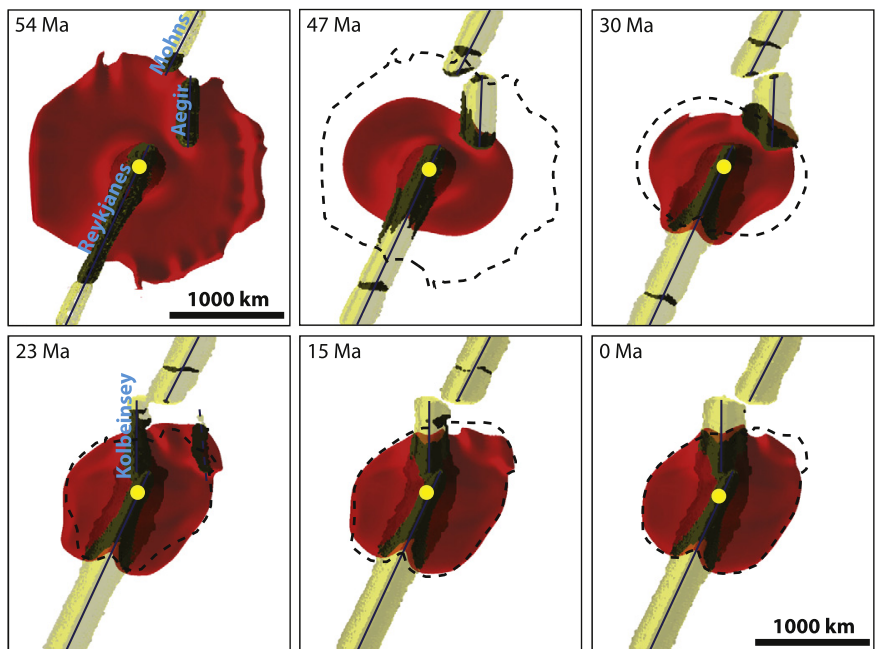

Fig. 5. Snap shots at different times of Model 3a (Table 1 ), which has a relatively high flux $\left(Q=232 \mathrm{~m}^{3} / \mathrm{s}\right)$, low Rayleigh number $\left(0.5 \times 10^{6}\right)$, and the lithosphere is thermally controlled (no dehydration rheology), illustrating the evolution of a typical model plume pancake of a hotspot centered beneath the yellow circles. Red isosurface envelops mantle with excess temperature $\geqslant 55^{\circ} \mathrm{C}$; yellow isosurface marks melt production; gray isosurface marks material melting that originated in the plume stem. Active spreading centers are marked with black lines. To show how the plume pancake changes between panels, the dashed black line outlines the plume pancake from the previous panel. (For interpretation of the references to color in this figure legend, the reader is referred to the web version of this article.)

The slight retraction in influence in the model KR basin near $23 \mathrm{Ma}$ is seen as narrow bands of plume influenced crust along the margins at the northern end of the basin next to small patches of uninfluenced seafloor. After this retraction, plume influence widens toward the present-day KR and recedes along the RR.

A lower plume flux (Model 8a, Fig. 6(b), (d)) yields a width of influence on the seafloor that is overall less than in the high flux case (Model 3a) after the initial contraction. Between the 47 and $25 \mathrm{Ma}$ isochrons, plume influence is seen to widen along RR while receding slightly (rather than widening as in Model 3a) along AR. The KR basin shows streaks of wide plume influence near the rifted margins, which are less pronounced than the solid bands of influence in Model 3a. Plume influence has widened along the KR from the minimum width near the continental margin to its present-day width, which is still increasing. In the RR basin, the width of influence decreases between the $25 \mathrm{Ma}$ isochron and present-day, similar to Model 3a.

In both of the models shown with a thermal lithosphere, crustal thickness (Fig. 6(c), (d)) is slightly enhanced near the continental margins (7-9 km) and greatest (90-140 km) along the volcanic ridge east and west of the plume center. However, the predicted crustal thickness at the continental margins is not overly thick (i.e., prior to $\sim 50 \mathrm{Ma}$ ), primarily because there is a predicted time lag between when rifting is first imposed and when the lithosphere is thin enough to allow for substantial decompression melting. This effect was shown to be overcome in previous numerical models by imposing the lithosphere to be $(\sim 50 \%)$ thinner beneath the rift zones than elsewhere in order to simulate rifting prior to the main continental breakup event (Nielsen and Hopper, 2004). On younger seafloor, shorter-wavelength variations in crustal thickness, $2-5 \mathrm{~km}$ in amplitude, are evident and extend 2-3 times further along RR in the high flux, compared to the low-flux case. These variations are caused by spatio-temporal variations in buoyancy-driven plume flow in the melting zone. Crust at the southern AR and KR is thickened by plume influence (11-14 km). Plume-thickened crust is present for about half the length of AR in the high-flux case (Model 3a), but is restricted to the southern quarter of the ridge in the low-flux case (Model 8a).

Relative to the above models with a thermal lithosphere (Models 3a, 8a), models with a dehydrated lithosphere and comparable plume fluxes (Models 4, 8b) predict a more dramatic initial contraction in plume influence during continental break-up, resulting in longer bands of plume-influenced margins adjacent to uninfluenced seafloor (Fig. 6(e), (f)). Between the 47 Ma isochrons, the overall width of plume influence is less with dehydrated lithosphere than with thermal lithosphere, with the largest difference occurring at the RR. The widths at the RR are more comparable to those at the AR indicating that the relatively flat base of the dehydrated lithosphere leads to a more symmetric plume pancake.

Models with a dehydrated lithosphere produce crustal thicknesses (Fig. 6(g), (h)) slightly thinner at the continental margins $(<8 \mathrm{~km})$ and much thinner along the east-west trending volcanic ridges (17-21 km), and lack the short-wavelength variations in crustal thickness seen in the thermal lithosphere cases, as buoyancy-driven flow in the dehydrated melting zone is suppressed by its high viscosity. Thickened crust extends a similar 

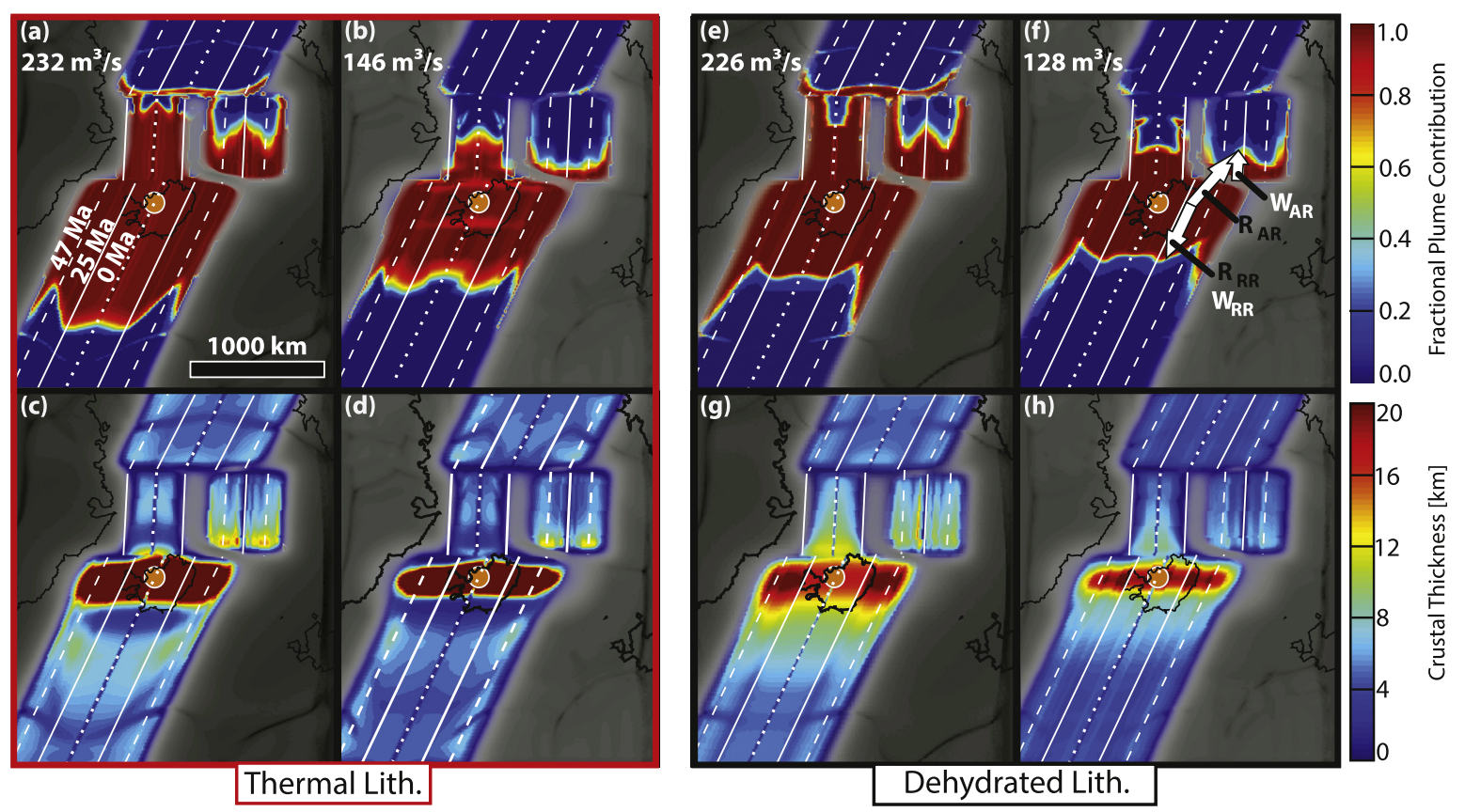

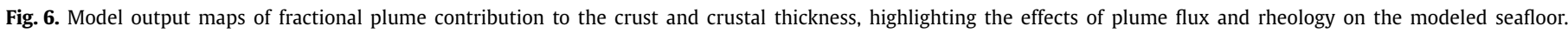

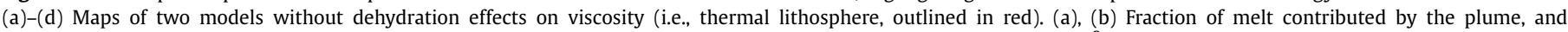

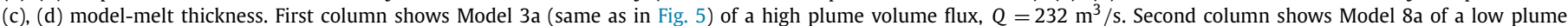

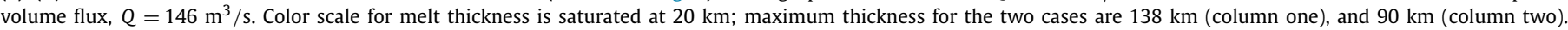

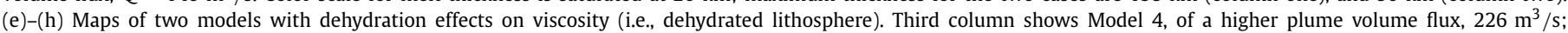

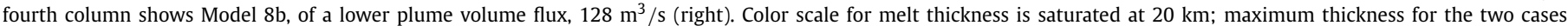

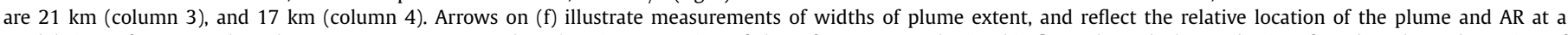

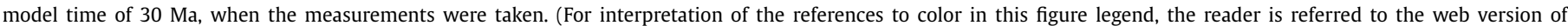
this article.)

distance along the AR and KR for the two rheologies, but the models with a dehydrated lithosphere yield a smaller maximum crustal thickness $(<9 \mathrm{~km})$ at the AR.

\subsection{Dependence of plume asymmetry on plume volume flux, viscosity, and rheology}

The radial asymmetry of the plume pancake, measured by the ratio of radial distances of influence along the two ridges, $R_{A R} / R_{R R}$, does not appear to change with plume flux, $Q$, and Rayleigh number, which is inversely proportional to plume viscosity (Fig. 7). Thus, the radial asymmetry does not seem to be influenced by the characteristic thickness, $S$, of the pancake (Eq. (2))-which again varies with $Q$ and/or $\eta$-over the range of thicknesses tested $(80-180 \mathrm{~km})$. The biggest difference in $R_{A R} / R_{R R}$ occurs between cases with and without dehydration. With a dehydrated lithosphere, the radial extent of influence along the AR is $70-80 \%$ that of the RR ( $R_{A R} / R_{R R}$ is $\left.\sim 0.7-0.8\right)$. Thus, even when the lithosphere is relatively flat, models show asymmetry in the radial extents of the plume pancake. This result is likely due to westward shear from the model North American Plate inhibiting NE plume flow to the AR, with no such inhibition SSW along the RR. This result strongly supports that the asymmetric geometry of the ridges, alone, leads to asymmetric hotspot influence (Hypothesis 1 ). With a thermal lithosphere, $R_{A R} / R_{R R}$ is $\sim 0.4-0.5$, indicating even greater asymmetry. In these cases, plume influence to the AR is inhibited not only by plate shear, but also by the large difference in lithospheric thickness across the transform between the RR and AR and the relatively thick thermal lithosphere of the JMMC, which has long been predicted to inhibit mantle flow between ridges (e.g. Vogt and Johnson, 1975). These results strongly support Hypothesis 2, that variations in lithospheric thickness can enhance the asymmetry of plume influence.
In contrast to the apparent insensitivity of $R_{A R} / R_{R R}$ to changes in $Q$, the ratio of widths along the ridges, $W_{A R} / W_{R R}$ changes appreciably with plume volume flux, $Q$ (Fig. 7(b)). $W_{A R} / W_{R R}$ increases with $Q$ due to the geometric effects of the gap between the plume center and the southern boundary of the Aegir Ridge. In a hypothetical case in which $Q$ is low enough that $R_{A R}$ is equal to the gap, $W_{A R}$ and $W_{A R} / W_{R R}$ would be zero. The proportional increase in $W_{A R}$ from zero with $Q$ is more rapid than the proportional increase in $W_{R R}$. The rate that $W_{A R} / W_{R R}$ increases with $Q$ is less in models with a thermal lithosphere than in models with a dehydrated lithosphere, reflecting a tendency of the former to promote a more asymmetric plume pancake. Rayleigh number (or viscosity) still has little, or no, effect on the asymmetry as measured by $W_{A R} / W_{R R}$.

\section{Discussion: Comparison of model predictions with observations}

\subsection{Asymmetry and plume influence}

Several aspects about the extents of plume influence as inferred from residual bathymetry in the North Atlantic (Fig. 1) can be interpreted based on our model predictions of plume-contributed crust. The residual bathymetry shows shallow continental margins, and thus plume-influenced thick igneous crust, which transitions to deeper seafloor, and thinner crust, over short seaward distances of $\sim 100 \mathrm{~km}$. We predict this transition to occur due to the rapid reduction in width of plume influence during continental rifting (Fig. 6). An observed minimum width of inferred plume influence is evident seaward of the continental margins in contours of residual bathymetry and, in the RR basin, by the appearance of rough basement topography created by orthogonal spreading of a segmented RR (White, 1997). From this minimum width, the influ- 


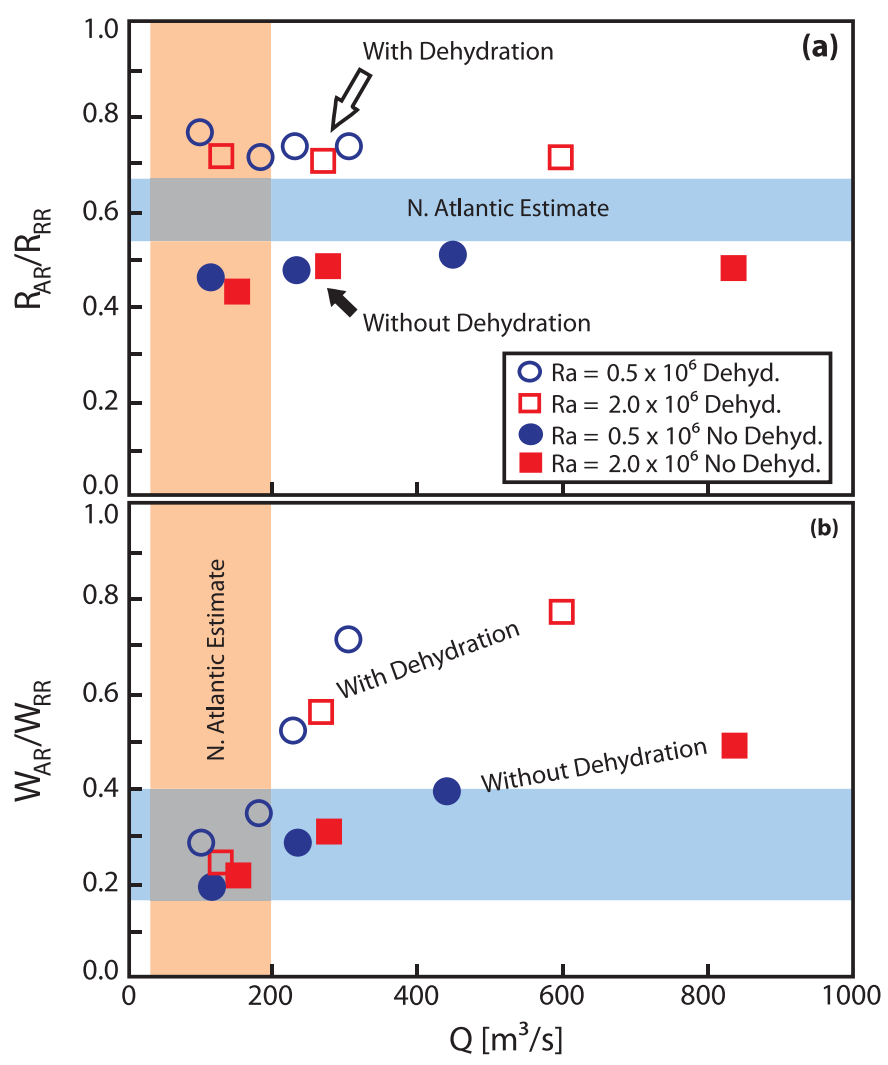

Fig. 7. Results of models run at two Rayleigh numbers describing the dependence of asymmetry ratios on plume flux, $Q$. (a) Ratio of radial extent of the plume along the Aegir Ridge, $R_{A R}$, relative to that along the Reykjanes Ridge, $R_{R R}$ (see Fig. $6(\mathrm{f})$ ) and (b) the ratio of width of plume influence along the Aegir Ridge axis, $W_{A R}$, to that along the Reykjanes Ridge axis, $W_{R R}$ (see Fig. 6(f)). Open and solid shapes represent cases with and without a dehydration rheology, respectively. Shaded blue bands show estimates for the same ratios with uncertainties for the Iceland hotspot as described in the text. Pink bands show estimates for Iceland plume flux that span values used over a range of studies (e.g. Ito et al., 1999; Ribe et al., 1995; Ribe and Delattre, 1998). (For interpretation of the references to color in this figure legend, the reader is referred to the web version of this article.)

ence of the plume appears to have extended farther south along the RR from $\sim 47-25 \mathrm{Ma}$, which is seen as the southward propagation along-axis of the rough-smooth boundary (Fig. 1). This southward plume expansion is another behavior predicted by the models (Fig. 6).

Near $25 \mathrm{Ma}$, which corresponds to the time that the AR becomes extinct and the KR is fully active, the rough-smooth axial topographic transition began to propagate SW along the RR. In contrast, the models predict the plume influence to retract back north along the RR as more plume material is drawn toward the KR during this time. The observed continued southward propagation of the rough-smooth boundary could signal an increase in the flux of the Iceland plume not simulated in the current models. This suggests that our models best represent the period when the AR was spreading ( $\sim 55-25 \mathrm{Ma})$. In the basin formed by the $\mathrm{KR}$, shallow residual topography (and thus inferred plume influence) is observed along the margins of Greenland and the JMMC (Fig. 1), much like the bands of plume-derived crust predicted in the models (Fig. 6).

To address the actual asymmetry of the Iceland hotspot along the Mid-Atlantic Ridge, we estimate $R_{A R} / R_{R R}$ and $W_{A R} / W_{R R}$ using the same criteria as the model analysis, applied to the reconstructed geometry (Müller et al., 2008) of the RR and AR at $30 \mathrm{Ma}$, again, the approximate age of oceanic crust along which Rai et al. (2012) seismic refraction profile ran. Distances of plume influence along the RR are found using the rough-smooth boundary in oceanic basement topography, and along the AR are based on where the seismically measured crustal thickness (Rai et al. (2012) is seen to abruptly increase. Uncertainties in the widths $\left(W_{A R}\right.$, $\left.W_{R R}\right)$ and radial distances $\left(R_{A R}, R_{R R}\right)$ include the uncertainty in the location of the center of the plume using the possible locations shown in Fig. 2. An additional uncertainty of $\sim 150 \mathrm{~km}$ in the width along the AR (marked in Fig. 8) arises from two locations where seismically determined crustal thickness increases abruptly from NE to SW.

Our estimates of $R_{A R} / R_{R R}$ and $W_{A R} / W_{R R}$ for the Iceland hotspot at $30 \mathrm{Ma}$ are $0.54-0.67$ and $0.18-0.40$, respectively (Fig. 7). When considering the model predictions for how $W_{A R} / W_{R R}$ changes with volume flux, $Q$, the estimated $W_{A R} / W_{R R}$ of the Iceland hotspot suggests a plume flux between $\sim 100-420 \mathrm{~m}^{3} / \mathrm{s}$ for a thermally controlled lithosphere, and $\sim 100-200 \mathrm{~m}^{3} / \mathrm{s}$ for a dehydrationcontrolled lithosphere. Both flux ranges are consistent with the flux $\left(200 \mathrm{~m}^{3} / \mathrm{s}\right)$ simulated by Ito et al. (1999) and the preferred flux $\left(193 \mathrm{~m}^{3} / \mathrm{s}\right)$ simulated by Ribe et al. (1995) for a ridge centered Iceland plume, which were based on predictions of the along-axis width $(1400-1600 \mathrm{~km})$ of the anomalously shallow topography and thick crust. The current flux estimates are greater than the published estimates $\left(30-45 \mathrm{~m}^{3} / \mathrm{s}\right)$ based on the narrower width of the geochemical anomaly of $\sim 920 \mathrm{~km}$ (Ribe and Delattre, 1998; Schilling, 1991). Our estimates of $R_{A R} / R_{R R}$ for the North Atlantic fall between model predictions for cases with and without dehydration stiffening (Fig. 7). This finding suggests that the rheology of the mantle is intermediate between the temperature- and dehydration- (plus temperature) dependent rheology simulated.

\subsection{Crustal thickness}

Seismically measured crustal thickness near the AR is compared with model predictions in Fig. 8. The first comparison is along the SE to NW seismic refraction transect from the Norwegian margin to the central portion of the AR (Fig. 3, Breivik et al., 2006, location marked in Fig. 1). As noted earlier, the models do not predict the large crustal thickness near the onset of rifting due to initially thick continental lithosphere inhibiting melting. From $\sim 50$ Ma onward, however, the models generally match the overall trend of the observed decreasing crustal thickness with time. Cases with higher versus lower Rayleigh numbers (lower versus higher average viscosity) produce thicker versus thinner crust at a similar plume volume flux. The models with a dehydrated lithosphere produce thinner crust and a more subtle decrease in crustal thickness over time compared to models with a thermal lithosphere. Cases with higher plume volume flux predict a wider plume pancake and thus produce thicker crust than those with lower flux. For both types of rheologies, models with a lower plume flux $\left(114-146 \mathrm{~m}^{3} / \mathrm{s}\right)$ predict crustal thicknesses qualitatively similar to those observed. This result supports those based on $W_{A R} / W_{R R}$ for plume fluxes of $100-200 \mathrm{~m}^{3} / \mathrm{s}$ (Fig. 7).

Fig. 8(c)-(d) shows model predictions of seismically derived crustal thickness (Rai et al., 2012) from south to north along the $\sim 30 \mathrm{Myr}$ isochron on the SE side of AR (location marked in Fig. 1). The seismic profile shows crustal thickness increasing southward in the southern half of AR, where spreading was slowest, and a more-or-less uniform crustal thickness in the northern half of the AR. Model calculations without a plume show no longwavelength change in crustal thickness along the AR (black curves, Fig. $8(\mathrm{c})-(\mathrm{d})$ ), in contrast to what is observed, which is further evidence for plume influence in the southern portion of the AR. Models with a dehydrated lithosphere produce thinner crust and a smaller southward increase in crustal thickness than the models with a thermal lithosphere. For both rheologies, models with the highest plume flux predict the plume to influence the whole AR and crust that is much thicker than observed. Models with 


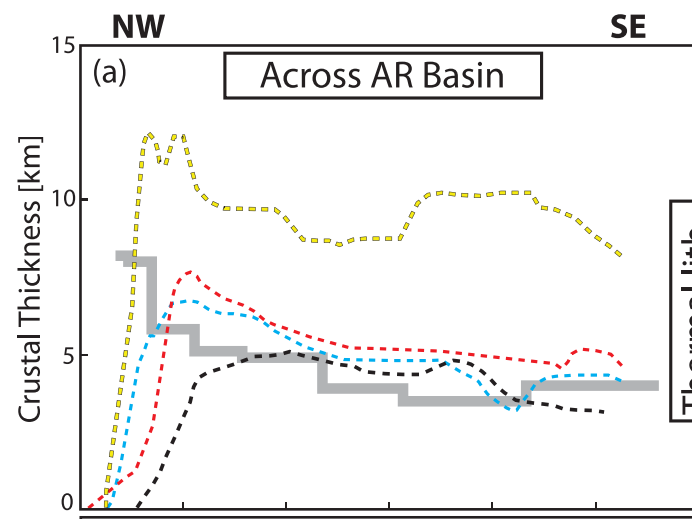
$\mathbf{S}$
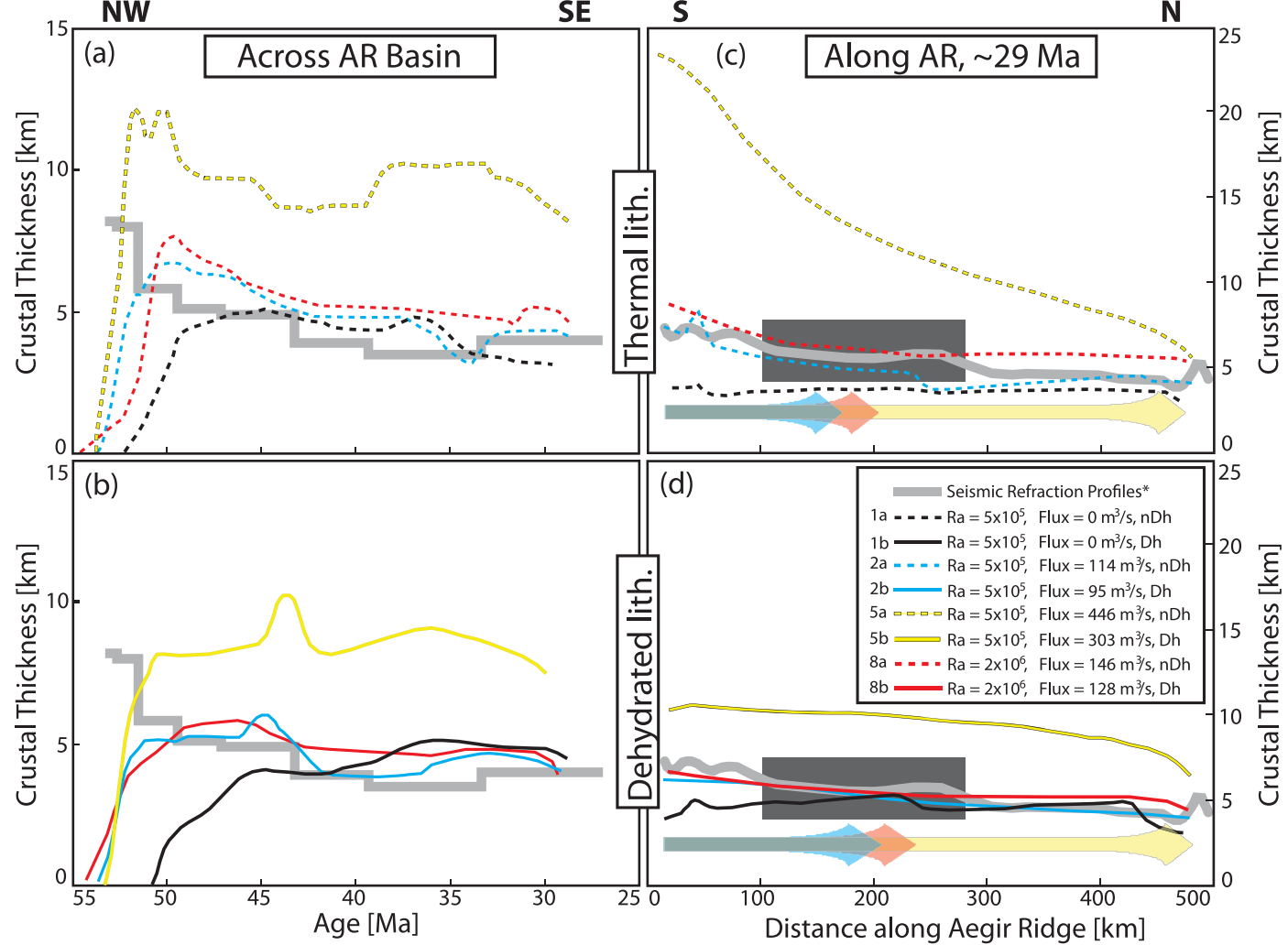

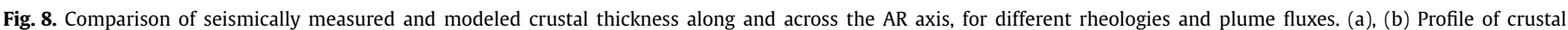

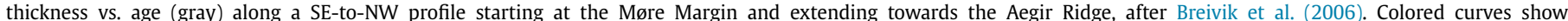

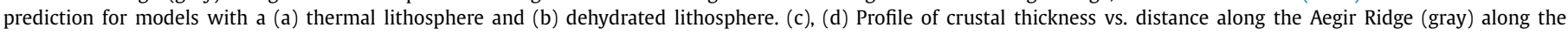

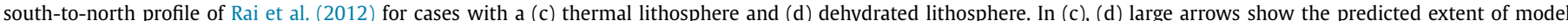

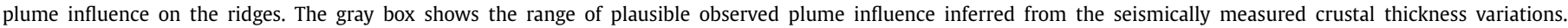
Models and their key parameters are labeled in the legend. Black solid and dashed lines are predictions of models without a plume.

lower plume flux predict the plume to influence only the southern part of the AR and crustal thicknesses similar to those observed. These results further support a plume with relatively low flux $\left(95-128 \mathrm{~m}^{3} / \mathrm{s}\right)$.

Crustal thickness measurements along the present-day MidAtlantic Ridge, starting at the KR in the north, extending south across Iceland and then along the RR, as presented by Hooft et al. (2006), are compared with model predictions in Fig. 9. In agreement with the seismic results, models show peaks in crustal thickness over the center of the plume on Iceland, a sharp decrease $\sim 200 \mathrm{~km}$ north and south of the peak, and gradual decreases in crustal thickness further from the plume center. Hooft et al. (2006) noted an asymmetry in the observed crustal thickness, with the crust along the KR, 200-500 km north of the plume center being 1-2 km thinner than that at the same distances south along the RR. The models with a dehydrated lithosphere predict the same sense of asymmetry, although slighter greater asymmetry than observed: the model crust is thinner by $\sim 2 \mathrm{~km}$ along the KR 200-350 km north of the plume center than the same distance south along the RR. The models with a thermal lithosphere do not predict this sense of asymmetry. In terms of maximum crustal thickness, the models with a dehydrated lithosphere predict thinner crust than observed, whereas the models with a thermal lithosphere predict significantly thicker crust than observed.

Our model predictions for the peak crustal thickness on Iceland, the asymmetry in crustal thickness along the present-day Mid-Atlantic Ridge, as well as the degree of radial asymmetry, measured by $R_{A R} / R_{R R}$, at $30 \mathrm{Ma}$ all suggest the actual rheology is intermediate between the two rheologies simulated. This result

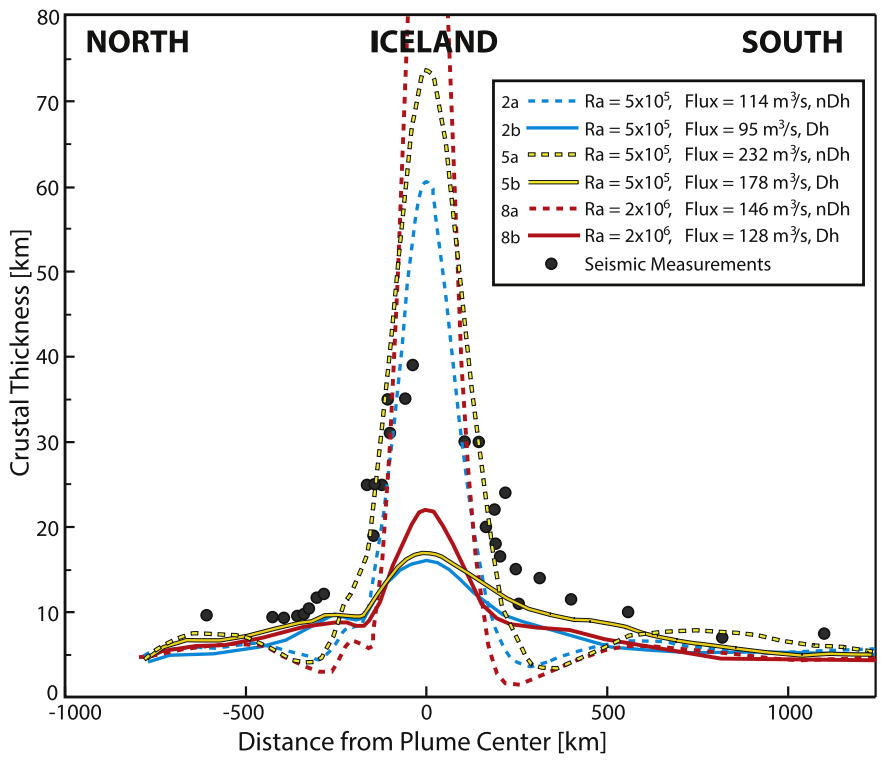

Fig. 9. A comparison of model predictions and observations along the present-day Mid-Atlantic Ridge. Curves are for the same models as in Fig. 8; solid and dashed lines depict models with and without dehydration stiffening, respectively. Filled circles represent seismic measurements presented by Hooft et al. (2006); colored curves show crustal thickness of model predictions versus distance from the center of the plume along the ridges. (For interpretation of the references to color in this figure legend, the reader is referred to the web version of this article.)

supports those of Reudas et al. (2004) whose models included a higher average viscosity than in our models without dehydration 
and produced better fits to Iceland's crustal thicknesses. We suggest that a viscous, dehydrated lithosphere is present at the Iceland hotspot, but is less viscous than we have simulated. An intermediate behavior may arise if the ambient viscosity of the North Atlantic upper mantle is even lower than that modeled, so that the dehydrated material too is less viscous. Alternatively, it is possible that non-Newtonian rheology leads to lower viscosities in the dehydrated layer, where strain rates are higher, such as above the plume or near the ridge axis (Ito et al., 2010). Another possibility is that the presence of even a small amount of melt in the mantle substantially reduces viscosity to partially negate the effects of dehydration strengthening (Takei and Holtzman, 2009).

\section{Conclusions}

Numerical models of plume-ridge interaction are used to study the cause of variations in the influence of the Iceland hotspot along the Mid-Atlantic Ridge and determine the origin of the NE-SW asymmetry evident in the residual topography and crustal thickness. Models initially simulate a plume pancake that spans the full width of the Greenland margin at the time of continental breakup. The pancake is then predicted to contract rapidly as some material is advected away from the newly formed ridge axis and the rest draws into the axial, sublithospheric trough, providing a simple explanation for the observed rapid narrowing of Iceland plume influence near the continental margins. Following this initial contraction, the plume pancake is predicted to widen southward along the Reykjanes Ridge (RR), resembling the observed southwardtrending, rough-smooth boundary east and west of the RR. To the northeast, the models with a lower plume flux predict the plume pancake to extend along only the southern part of the Aegir Ridge (AR), which is consistent with seismic measurements of crustal thickness along the AR. The observed southward convergence (east and west towards the RR axis) of the two rough-smooth boundaries in basement topography on crust younger than $25 \mathrm{Ma}$, after spreading shifted from the AR to $K R$, is not predicted by the models and could signal an increase in the Iceland plume flux since this time.

All models predict the plume pancake to spread less far along the AR than along the RR. The ratio of radial extents of plume influence along the AR and $\mathrm{RR}\left(R_{A R} / R_{R R}\right)$ is predicted to be insensitive to changes in plume volume flux and viscosity, and varies primarily with changes in rheology. When the lithosphere is controlled by dehydration, the plume expands $70-80 \%$ as far along the $\mathrm{AR}$ as it does along the $\mathrm{RR}\left(R_{A R} / R_{R R}=0.7-0.8\right)$. This result indicates that the asymmetry is caused partly by the asymmetric configuration of the ridges relative to the plume center (ridge geometry control, hypothesis 1 ). In models with a thermal lithosphere, $R_{A R} / R_{R R}=0.4-0.5$. This enhanced asymmetry is associated with the topography of the base of a thermal lithosphere (lithosphere thickness variation, hypotheses 2 ) that is not present with a dehydrated lithosphere.

Models with Iceland plume volume fluxes of $100-200 \mathrm{~m}^{3} / \mathrm{s}$ best explain observed ratios of the widths of plume influence along the AR and $\mathrm{RR}\left(W_{R R} / W_{A R}\right)$, as well as crustal thickness along the RR and AR at $\sim 30$ Ma. Comparisons of observed and modeled asymmetry in radial distance of plume influence $\left(R_{A R} / R_{R R}\right)$ at $30 \mathrm{Ma}$ and crustal thickness along the present-day Mid-Atlantic ridge suggest that a there is a dehydrated lithosphere, but one that is less viscous than simulated in models. The observed asymmetry in crustal thickness along the present-day ridge is predicted to be the result of the plume approaching a steady width along the RR, while still widening (since rifting began $\sim 25 \mathrm{Ma}$ ) along the Kolbeinsey Ridge.

\section{Acknowledgements}

We owe our gratitude to the captain and crew of the R/V Håkon Mosby for their invaluable contributions to the ARGGH2010 cruise, and to the University of Bergen for travel support. We extend our appreciation to the editor Dr. Yanick Ricard and two anonymous reviewers for offering critical, thorough reviews of this paper. This research was supported by NSF grants EAR-0855814 and OCE-0852115.

\section{Appendix A. Supplementary material}

Supplementary material related to this article can be found online at http://dx.doi.org/10.1016/j.epsl.2014.02.020.

\section{References}

Allen, R.M., Nolet, G., Morgan, W.J., Vogfjord, K., Bergsson, B.H., Erlendsson, P., Foulger, G.R., Jakobsdottir, S., Julian, B.R., Pritchard, M., Ragnarsson, S., Stefansson, R. 2002. Imaging the mantle beneath Iceland using integrated seismological techniques. J. Geophys. Res. 107. http://dx.doi.org/10.1029/2001JB000595.

Bianco, T.A., Ito, G., van Hunen, J., Ballmer, M.D., Mahoney, J.J., 2011. Geochemical variation at intraplate hot spots caused by variable melting of a veined mantle plume. Geochem. Geophys. Geosyst.. http://dx.doi.org/10.1029/2011GC003658.

Breivik, A.J., Faleide, J.I., Mjelde, R., Flueh, E.R., 2009. Magma productivity and early seafloor spreading rate correlation on the northern Vøring Margin, Norway-Constraints on mantle melting. Tectonophysics. http://dx.doi.org/ 10.1016/j.tecto.2008.1009.1020.

Breivik, A.J., Mjelde, R., Faleide, J.I., Murai, Y., 2006. Rates of continental breakup magmatism and seafloor spreading in the Norway Basin-Iceland plume interaction. J. Geophys. Res. 111, B07102.

Coffin, M.F., Eldholm, O., 1994. Large igneous provinces: Crustal structure, dimensions, and external consequences. Rev. Geophys. 32, 1-36.

Dick, H.J.B., Lin, J., Schouten, H., 2003. An ultraslow-spreading class of ocean ridge. Nature 426, 405-412.

Garcia, S., Angelier, J., Bergarat, F., Homberg, C., Dauteuil, O., 2008. Influence of rift jump and excess loading on the structural evolution of northern Iceland. Tectonics. http://dx.doi.org/10.1029/2006TC002029.

Hardarson, B.S., Fitton, J.G., Ellam, R.M., Pringle, M.S., 1997. Rift relocation-a geochemical and geochronological investigation of a paleo-rift in northwest Iceland Earth Planet. Sci. Lett. 153, 181-196.

Hirth, G., Kohlstaedt, D.L., 2003. Rheology of the upper mantle and the mantle wedge: A view from the experimentalists. In: Eiler, J. (Ed.), Inside the Subduction Factory. In: Geophys. Monogr. Ser.. AGU, Washington DC, pp. 83-105.

Holbrook, W.S., Larsen, H.C., Korenaga, J., Dahl-Jensen, T., Reid, I.D., Kelemen, P.B., Hopper, J.R., Kent, G.M., Lizarralde, D., Bernstein, S., Detrick, R.S., 2001. Mantle thermal structure and active upwelling during continental breakup in the North Atlantic. Earth Planet. Sci. Lett. 190, 251-266.

Hooft, E.E., Brandsdottir, B., Mjelde, R., Shimamura, H., Murai, Y., 2006. Asymmetric plume-ridge interaction around Iceland: The Kolbeinsey Ridge Iceland Seismic Experiment. Geochem. Geophys. Geosyst. 7, 1-26.

Ito, G., Dunn, R., Forsyth, D.W., 2010. A study of short-period surface wave data geodynamic models, and the rheology and dynamics of the mantle beneath the East-Pacific Rise. In: Fall Meeting. AGU, San Francisco, CA. Abstract DI34A-01.

Ito, G., Shen, Y., Hirth, G., Wolfe, C., 1999. Mantle flow, melting, and dehydration of the Iceland mantle plume. Earth Planet. Sci. Lett. 165, 81-96.

Ito, G., van Keken, P.E., 2007. Hot spots and melting anomalies. In: Bercovici, D. (Ed.), Mantle Dynamics. Elsevier, Amsterdam, The Netherlands, pp. 371-435.

Katz, R.F., Spiegelman, M., Langmuir, C.H., 2003. A new parameterization of hydrous mantle melting. Geochem. Geophys. Geosyst. 4, 173. http://dx.doi.org 10.1029/2002GC000433.

Lawver, L.A., Müller, R.D., 1994. The Iceland hotspot track. Geology 22, 311-314.

Mihalffy, P., Steinberger, B., Schmeling, H., 2008. The effect of the large-scale mantle flow field on the Iceland hotspot track. Tectonophysics 447, 5-18.

Mjelde, R., Breivik, A.J., Raum Mittelstaedt E, T., Ito, G., Faleide, J.I., 2008. Magmatic and tectonic evolution of the North Atlantic. J. Geol. Soc. 165, 32-42.

Mjelde, R., Raum, T., Myhren, B., Shimamura, H., Murai, Y., Takanami, T., Karpuz, R., Næss, U., 2005. Continent-ocean transition on the Vøring Plateau, NE Atlantic, derived from densely sampled ocean bottom seismometer data. J. Geophys. Res. 110. http://dx.doi.org/10.1029/2004JB003026.

Moresi, L., Gurnis, M., 1996. Constraints on the lateral strength of slabs from threedimensional dynamic flow models. Earth Planet. Sci. Lett. 138, 15-28.

Mosar, J., Lewis, G., Torsvik, T.H., 2002. North Atlantic sea-floor spreading rates: implications for the Tertiary development of inversion structures of the Norwegian-Greenland Sea. J. Geol. Soc. Lond. 158, 503-515.

Müller, R.D., Sdrolias, M., Gaina, C., Roest, W.R., 2008. Age, spreading rates, and spreading symmetry of the world's ocean crust. Geochem. Geophys. Geosyst. 9 Q04006. 
Nielsen, T.K., Hopper, J.R., 2004. From rift to drift: Mantle melting during continental breakup. Geochem. Geophys. Geosyst. 5, 7. http://dx.doi.org/10.1029/ 2003GC000662.

Nunns, A.G., 1983. Plate tectonic evolution of the Greenland-Scotland Ridge and surrounding regions. In: Bott, M.H.P., Saxow, S., Talwani, M., Thiede, J. (Eds.), Structure and Development of the Greenland-Scotland Ridge: New Methods and Concepts. NATO Advanced Research Institute/Plenum Press, New York, NY, pp. 11-30.

Rai, A.K., Breivik, A.J., Mjelde, R., Hanan, B.B., Ito, G., Sayit, K., Howell, S., Vogt, P.R. Pedersen, R.-B., 2012. Analysis of converted S-waves and gravity anomaly along the Aegir Ridge: implications for crustal lithology. In: Fall Meeting. AGU, San Francisco. Abstract T31B-2587.

Reudas, T., Schmeling, H., Marquart, G., Kreutzmann, A., Junge, A., 2004. Temperature and melting of a ridge-centred plume with application to Iceland. Part I: Dynamics and crust production. Geophys. J. Int. 158, 729-743.

Ribe, N., Christensen, U.R., Theissing, J., 1995. The dynamics of plume-ridge interaction, 1: Ridge-centered plumes. Earth Planet. Sci. Lett. 134, 155-168.

Ribe, N., Delattre, W.L., 1998. The dynamics of plume-ridge interaction, 3: The effects of ridge migration. Geophys. J. Int. 133, 511-518.

Schilling, J.G., 1991. Fluxes and excess temperatures of mantle plumes inferred from their interaction with migrating mid-ocean ridges. Nature 352, 397-403.

Schilling, J.-G., 1999. Dispersion of the Jan Mayen and Iceland mantle plumes in the Arctic: A He-Pb-Nd-Sr isotope tracer study of basalts from the Kolbeinsey, Mohns, and Knipovich Ridges. J. Geophys. Res. 104, 10,543-10,569.

Schilling, J.-G., Zajax, M., Evans, R., Johnston, T., White, W., Devine, J.D., Kingsley, R. 1983. Petrologic and geochemical variations along the Mid-Atlantic Ridge from $29^{\circ} \mathrm{N}$ to $73^{\circ} \mathrm{N}$. Am. J. Sci. 283, 510-586.

Shorttle, O., Maclennan, J., Jones, S.M., 2010. Control of the symmetry of plumeridge interaction by spreading ridge geometry. Geochem. Geophys. Geosyst. http://dx.doi.org/10.1029/2009GC002986.

Smallwood, J.R., Staples, R.K., Richardson, K.R., White, R.S., 1999. Crust generated above the Iceland mantle plume: From continental rift to oceanic spreading center. J. Geophys. Res. 104, 22,885-22,902.

Smallwood, J.R., White, R.S., 2002. Ridge-plume interaction in the North Atlantic and its influence on continental breakup and seafloor spreading. Special Publications, vol. 197. Geological Society, London, pp. 15-37.

Steinberger, B., 2000. Plumes in a convecting mantle: Models and observations for individual hotspots. J. Geophys. Res. 105, 11,127-11,152.
Takei, Y., Holtzman, B.K., 2009. Viscous constitutive relations of solid-liquid composites in terms of grain boundary contiguity: 1. Grain boundary diffusion control model. J. Geophys. Res.. http://dx.doi.org/10.1029/2008JB005850.

Torsvik, T.H., Van der Voo, R., Meert, J.G., Mosar, J., Walderhaug, H.J., 2001. Reconstructions of the continents around the North Atlantic at about the 60th parallel. Earth Planet. Sci. Lett. 187, 55-69.

Vink, G.E., 1984. A hotspot model for Iceland and the Voring Plateau. J. Geophys. Res. 89, 9949-9959.

Vogt, P.R., Avery, E., 1974. Detailed magnetic surveys in the Northeast Atlantic and Labrador Sea. J. Geophys. Res. 79, 363-389.

Vogt, P.R., Johnson, G.L., 1975. Transform faults and longitudinal flow below the midoceanic ridge. J. Geophys. Res. 80, 1399-1428.

Vogt, P.R., Johnson, G.L., Kristjansson, L., 1980. Morphology and magnetic anomalies north of Iceland. J. Geophys. Res., 67-80.

Vogt, P.R., Kovacs, L.C., Bernero, C., Srivastava, S.P., 1982. Asymmetric geophysical signatures in the Greenland-Norwegian and Southern Labrador seas and the Eurasia Basin. Tectonophysics 89, 95-160.

Vogt, P.R., Perry, R.K., Feden, R.H., Fleming, H.S., Cherkis, N.Z., 1981. The GreenlandNorwegian Sea and Iceland environment: Geology and geophysics. In: Nairn, A.E.M., Churkin Jr., M., Stehli, F.G. (Eds.), The Ocean Basins and Margins: The Arctic Ocean. Plenum, New York, pp. 493-598.

Voss, M., Schmidt-Aursch, M.C., Jokat, W., 2009. Variations in magmatic processes along the East Greenland volcanic margin. Geophys. J. Int. 177, 755-782.

White, R.S., 1988. A hot-spot model for early Tertiary volcanism in the N Atlantic. Geol. Soc. Spec. Publ. 39, 3-13.

White, R.S., 1997. Rift-plume interaction in the North Atlantic. Philos. Trans. R. Soc. Lond. A 355, 319-339.

White, R., McKenzie, D., 1989. Magmatism at rift zones: The generation of volcanic continental margins and flood basalts. J. Geophys. Res. 94, 7685-7729.

White, R.S., Minshull, T.A., Bickle, M.J., Robinson, C.J., 2001. Melt generation at very slow-spreading oceanic ridges: constraints from geochemical and geophysical data. J. Petrol. 42, 1171-1196.

Wilson, J.T., 1973. Mantle plumes and plate motions. Tectonophysics 19, 149-164.

Wolfe, C., Bjarnason, I.T., VanDecar, J.C., Solomon, S.C., 1997. Seismic structure of the Iceland mantle plume. Nature 385, 245-247.

Zhong, S., Zuber, M.T., Moresi, L.N., Gurnis, M., 2000. The role of temperature dependent viscosity and surface plates in spherical shell models of mantle convection. J. Geophys. Res. 105, 11,063-11,082. 